\title{
An Assessment of Nominal and Actual Hourly Production of the Construction Equipment Based on Several Earth-Fill Dam Projects in Iran
}

\author{
Hamed Nabizadeh Rafsanjani*, Yaghoob Gholipour and Hassan Hosseini Ranjbar
}

University of Tehran, University of Tehran and Iran University of Science and Technology

\begin{abstract}
Optimum planning for heavy construction equipment is a vital task in succeeding the construction projects. In a construction plan one should significantly concentrate on the type, number and schedule of presence of the equipment at the project site. In this paper, we have studied the hourly production of a model of dozer, a wheel-type loader, a crawlertype loader, a grader, a crawler-type excavator, a sheepsfoot roller and a smooth wheel roller, at the site of several earthfill dams around Iran. Each model was individually considered and the site conditions were taken into account. The nominal hourly production of the equipment was derived according to the data obtained from Caterpillar, Komatsu, and Volvo manufacturers. The actual production was calculated according to the statistical data from various earth-fill dams in Iran. The derived results showed that the actual production of a sheepsfoot roller had the least difference with its nominal production; whilst the loader had the most difference in actual and nominal production (i.e. it had the lowest working efficiency).
\end{abstract}

Key Words: Construction equipment, Nominal hourly production, Actual hourly production, Earth-fill dam projects.

\section{INTRODUCTION}

It has been universally accepted that the equipment hourly production is one of the key factors in construction projects. It is also well known that the actual hourly production of the equipment differs from the nominal hourly production provided by the manufacturers. Increasing the actual hourly production has always been an ideal aim in achieving success throughout large scale earthmoving construction projects. Estimating this parameter is a key element in estimating the time and cost required to terminate the construction operations (Oglesby et al. 1989 [1]). The accurate estimation of earthmoving hourly production has intrigued many researchers for many years (Alkass and Harris 1988 [2]; Amirkhanian and Baker 1992 [3]; Karshenas and Feng 1992 [4]; Smith 1999 [5]), and yet there is no robust model for prediction of the hourly production of earthmoving activities at the construction site (Seung and Sunil, 2006 [6]). Apparently, each manufacturer provides the users with an ideal hourly production plan, according to the equipment's specifications. It should be taken into account that the actual production at the site is different from the nominal production given by the manufacturer and depends mainly on the condition of the site. Thus, determining the actual production will make considerable help in gaining a more suitable planning for the construction equipment which would, in turn, lead to a more accurate planning throughout the project. Edmonds et al. (1994) [7] have taken actual production into account. They viewed the actual production as a percentage of full capacity, which provided a better measurement of the actual hourly production. In their

*Address correspondence to this author at the School of Civil Engineering, Faculty of Engineering, University of Tehran, 16 Azar Avenue, Tehran, Iran; Tel/Fax: +982161112177; E-mail: hamednabi@ut.ac.ir research, the actual production of the equipment has been estimated as approximately 52.5 percent of the nominal production. They used several methods such as the short range analysis, analysis of running time and analysis of running speed. The richness of analysis was said to be reduced when traditional techniques are used. In 2002, Bhurisith and Touran [8] studied the equipment production in a certain period of time, according to the equipment models. In this paper a comparison has been made between nominal hourly production and unit cost results obtained through different years and average rage of change are calculated. Their investigation was based on six equipment models, studied through a fifteen year period. In 2006, Zou [9] studied the effect of site conditions on equipment production using the HSV Color Space Digital Image Processing method. He tried to achieve more realistic results using the mentioned method.

\section{OBJECTIVE}

The main objective of this paper is to determine the actual production of different construction equipment according to their power. This information could certainly be useful in planning equipment and is a great help to the project management team.

\section{METHODOLOGY}

\subsection{Definitions}

- Nominal production: the production given by the manufacturer, which recognizes an ideal production while the equipment is operated on a continuous basis.

- Actual production: the production of the equipment at the site and is, obviously, less than the nominal production. Thus, the more efficient it is estimated, the better result would be obtained from managing the project. 


\subsection{Equipment Selection}

The choice of equipment in our study is limited to three manufacturers, namely, Caterpillar, Komatsu and Volvo. Caterpillar is believed to control more than $45 \%$ of the U.S. construction equipment market and $35 \%$ of the world market (Arditi et al. 1997 [10]). Since these manufacturers are amongst the most creditable heavy construction equipment suppliers all over the world, the obtained results could be applicable for the whole heavy equipment industry. The equipment studied here, has been chosen according to their application in earth-fill dams. For instance, Volvo loaders are used in most of the dam projects.

\subsection{Data Sources}

The data for the nominal hourly production was estimated using the performance handbooks and construction charts. The data for the actual production analysis was collected from various earth-fill dams constructed around Iran. The location of the dams being investigated has been shown in Fig. (1). Fig. (2) presents the distribution of rainfall in the investigated projects. Although the dams are located in areas containing similar soil and climate condition but the annual rainfall has a significant effect on the equipment efficiency. However, concerning the small difference in the annual rainfall (less than 10\%), this parameter has been neglected in our calculations. The actual production for seven various types of heavy equipment which played the main role in dam construction, was estimated according to the site conditions.

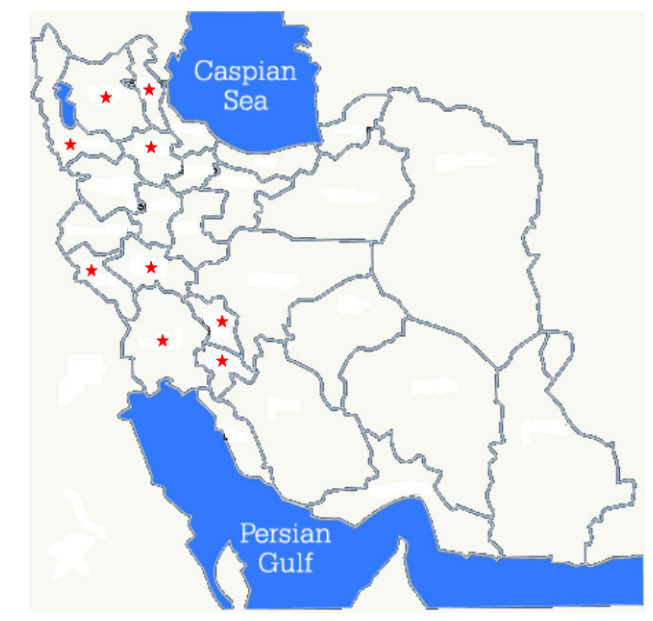

Fig. (1). Project locations.

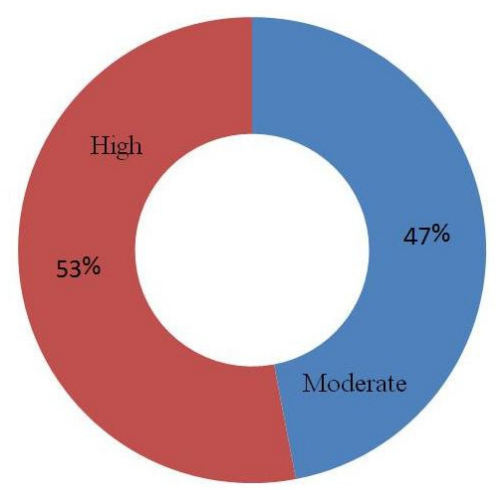

Fig. (2). Distribution of rainfall.

\subsection{Production Estimation}

The actual construction conditions at various project sites differ according to the climate, the soil type, equipment age and the driver's workmanship. The equipment were divided into four groups based on their ages. Fig. (3) presents the distribution of four age groups. As shown in the Fig. (4), the majority of the driver $(62 \%)$ had more than ten years construction working experience.

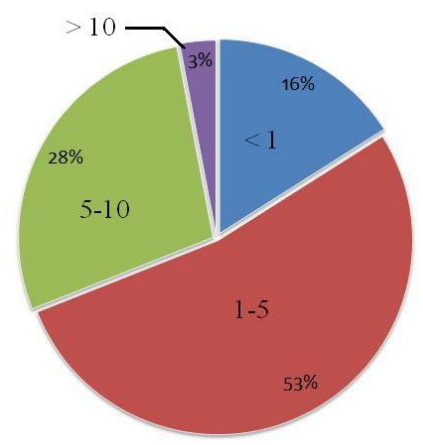

Fig. (3). Distribution of age group of equipment (years).

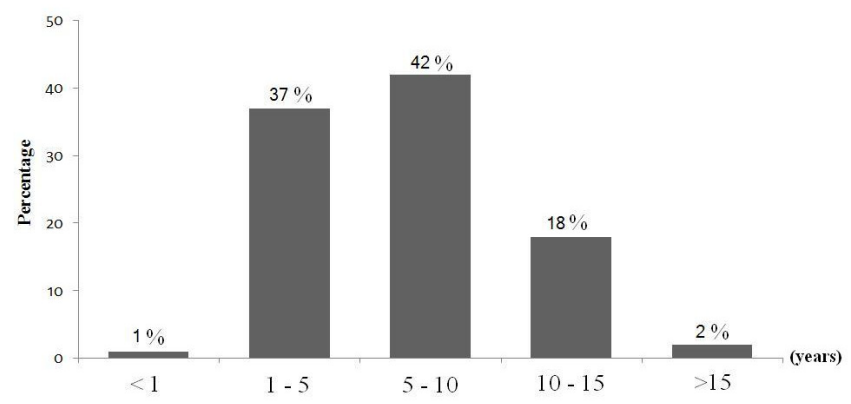

Fig. (4). Distribution of years working experience of drivers.

\subsection{Data Analysis}

In our study, the actual production of the equipment was derived according to the following Analysis.

\subsubsection{Long-Range Analysis}

The more the equipment and work conditions are considered, the better result are achieved. Thus, the analysis of the falls in nominal hourly production may contribute to a more effective management of machine efficiency. Long range analysis is a reliable method for this purpose. In this analysis, the actual hourly production of equipment at the site project is obtained and the effective factors causing the shortfall are considered. For example, the running speed and accordingly, running time of the equipment may cause a significant difference between actual and nominal productions. There are several elements preventing full capacity construction. These non-productive time elements include setup time, scheduled maintenance and operation disengagement (e.g. meals and breaks.) At this level, the equipment models were classified according to their power (hp). For example, for a wheel-type loader with a power of 260 $\mathrm{hp}, 3$ various models were studied. The model $972 \mathrm{G}$ from Caterpillar, the model WA450-3MC from Komatsu, and the model L150F from Volvo, all having a power of $260 \mathrm{hp}$ were 
chosen; their nominal hourly production and actual production at the site were estimated.

\subsubsection{Ratio Analysis}

In order to verify the actual production in accordance to time duration a ratio analysis is also required, so that one should obtain approximately the same ratio for the given hourly production.

$\frac{2 \text { hour production }}{2} \approx \frac{1 \text { hour production }}{1} \approx \frac{\text { half hour production }}{1 / 2}$

\subsubsection{Variance Analysis}

Analysis of variance is an effective tool for analyzing pure experimental data (e.g. industrial experiments in which multiple factors may be altered at different times and in different locations). This analysis for a model with limited variable is as follow:

1. The expected value of the collected data is calculated. This value, $\mathrm{E}(\mathrm{x})$, is given by:

$$
E(x)=\left(x_{1}+x_{2}+\ldots+x_{n}\right) / n
$$

2. The variance is calculated according to:

$\operatorname{Var}(x)=E\left[(x-E(x))^{2}\right]$

3. The standard deviation, $\sigma(x)$, is calculated:

$$
\sigma(x)=\sqrt{\operatorname{Var}(x)}
$$

The value analysis carried out on the data is shown in the Table 1. In the first step, the standard deviation is compared with the expected value as well as comparing the expected value to the initial data, resulting in the omission of four of the values achieved. Thus the expected value is taken as the actual hourly production value.

\section{RESULTS}

By applying the above mentioned methodology the obtained results are given in the following Tables for various equipment models. The actual production for a grader, a smooth wheel roller, a sheep-foot roller, a dozer, a wheeltype loader, a crawler-type loader, and for a crawler type excavator are given in Tables $2,3,4,5,6,7$ and 8 , respectively.

The actual production given in the above Tables is based on an efficiency factor of $100 \%$. In the Tables below [9-12] some different working conditions were considered. The Tables are organized using performance handbooks and standard construction equipment books given in the references [1, 7, 11-14]. Depending on the project conditions, it is reasonable to apply these coefficients, in order to achieve more realistic results. Namely, the actual production of a dozer with an engine horsepower of $150 \mathrm{hp}$, a bucket capacity of 2 cubic meters, haul distance of 15 meters with +10 ground slope, working in medium conditions containing blaster rock is as following:

$150\left(\mathrm{~m}^{3} / \mathrm{hr}\right) \times 0.75 \times 0.5 \times 0.86=48\left(\mathrm{~m}^{3} / \mathrm{hr}\right)$

\section{CONCLUSION}

This paper has explored the actual hourly production of seven different pieces of earthmoving equipment of earthfill dam projects in Iran by using a three-stage statistical analysis. The actual hourly production of the equipment can effectively contribute to the management of the construction projects. A sheepsfoot roller shows the lowest efficiency with an actual to nominal hourly production ratio of 0.32 whilst the wheel loader shows the highest efficiency with a ratio of 0.6. A loader shows the lowest shortfall, with a constant actual to nominal hourly production ratio of 0.6 for various engine horse powers, whereas the highest range of variation of 0.5 is observed for a dozer.

\section{ACKNOWLEDGEMENT}

This study was supported by the MahabGhodss Company, a leading company in dam construction all over Iran. The authors are very grateful to the referees for their constructive comments.

Table 1. Actual Hourly Production Data A Wheel-Type Loader with A Power of 260 hp

\begin{tabular}{|c|c|c|c|c|c|c|c|c|c|c|c|c|}
\hline \multicolumn{10}{|c|}{ Actual Hourly Production Data } & $\mathbf{E}(\mathbf{x})$ & $\operatorname{Var}(\mathbf{x})$ & $\sigma(x)$ \\
\hline 257 & 264 & 286 & 235 & 267 & 276 & 281 & 277 & 279 & 268 & \multirow{2}{*}{267.55} & \multirow{2}{*}{276.23} & \multirow{2}{*}{16.62} \\
\hline 245 & 287 & 285 & 276 & 231 & 263 & 243 & 279 & 280 & 272 & & & \\
\hline
\end{tabular}
(a) first analysis

\begin{tabular}{|c|c|c|c|c|c|c|c|c|c|c|c|c|}
\hline \multicolumn{10}{|c|}{ Actual Hourly Production Data } & $\mathbf{E}(\mathbf{x})$ & $\operatorname{Var}(\mathbf{x})$ & $\sigma(x)$ \\
\hline 257 & 264 & 286 & & 267 & 281 & 276 & 287 & 279 & 268 & \multirow{2}{*}{274.81} & \multirow{2}{*}{73.44} & \multirow{2}{*}{8.57} \\
\hline & 277 & 285 & 276 & & 263 & & 279 & 280 & 272 & & & \\
\hline
\end{tabular}

(b) second analysis 
Table 2. Grader Hourly Production

\begin{tabular}{|c|c|c|c|c|}
\hline Engine Horsepower (hp) & Blade Length $(\mathbf{m})$ & Blade Height $(\mathbf{m})$ & $\begin{array}{c}\text { Nominal Work Hourly } \\
\text { Production }\left(\mathbf{m}^{3} / \mathbf{h r}\right)\end{array}$ & $\begin{array}{c}\text { Actual Work Hourly } \\
\text { Production }\left(\mathbf{m}^{\mathbf{3}} / \mathbf{h r}\right)\end{array}$ \\
\hline \hline 125 & 3.66 & 0.61 & 355 \\
\hline 135 & 3.66 & 0.61 & 383 & 301 \\
\hline 150 & 3.96 & 0.70 & 427 & 301 \\
\hline 180 & 3.66 & 0.61 & 569 & 337 \\
\hline 200 & 4.27 & 0.686 & 1145 & 361 \\
\hline
\end{tabular}

Table 3. Smooth Wheel Roller Hourly Production

\begin{tabular}{|c|c|c|c|c|c|}
\hline $\begin{array}{c}\text { Engine } \\
\text { Horsepower (hp) }\end{array}$ & $\begin{array}{c}\text { Operational } \\
\text { Weight }\end{array}$ & Gradeability & Working Conditions & $\begin{array}{c}\text { Nominal Work Hourly } \\
\text { Production }\left(\mathbf{m}^{3} / \mathbf{h r}\right)\end{array}$ & $\begin{array}{c}\text { Actual Work Hourly } \\
\text { Production }\left(\mathbf{m}^{3} / \mathbf{h r}\right)\end{array}$ \\
\hline \hline 77 & $4000 \sim 4500$ & $49 \%$ & $\begin{array}{c}4 \text { Cycles, Layer } \\
\text { thickness of } 150 \mathrm{~mm}\end{array}$ & 230 \\
\hline 102 & $6000 \sim 6500$ & $30 \%$ & $\begin{array}{c}4 \text { Cycles, Layer } \\
\text { thickness of } 150 \mathrm{~mm}\end{array}$ & 250 \\
\hline 102 & $6500 \sim 6800$ & $50 \%$ & $\begin{array}{c}4 \text { Cycles, Layer } \\
\text { thickness of } 150 \mathrm{~mm}\end{array}$ & 300 \\
\hline 155 & $10000 \sim 10500$ & $33 \%$ & $\begin{array}{c}4 \text { Cycles, Layer } \\
\text { thickness of } 150 \mathrm{~mm}\end{array}$ & 100 \\
\hline 155 & $10500 \sim 11000$ & $45 \%$ & $\begin{array}{c}4 \text { Cycles, Layer } \\
\text { thickness of } 150 \mathrm{~mm}\end{array}$ & 310 \\
\hline
\end{tabular}

Table 4. Sheep-Foot Roller Hourly Production

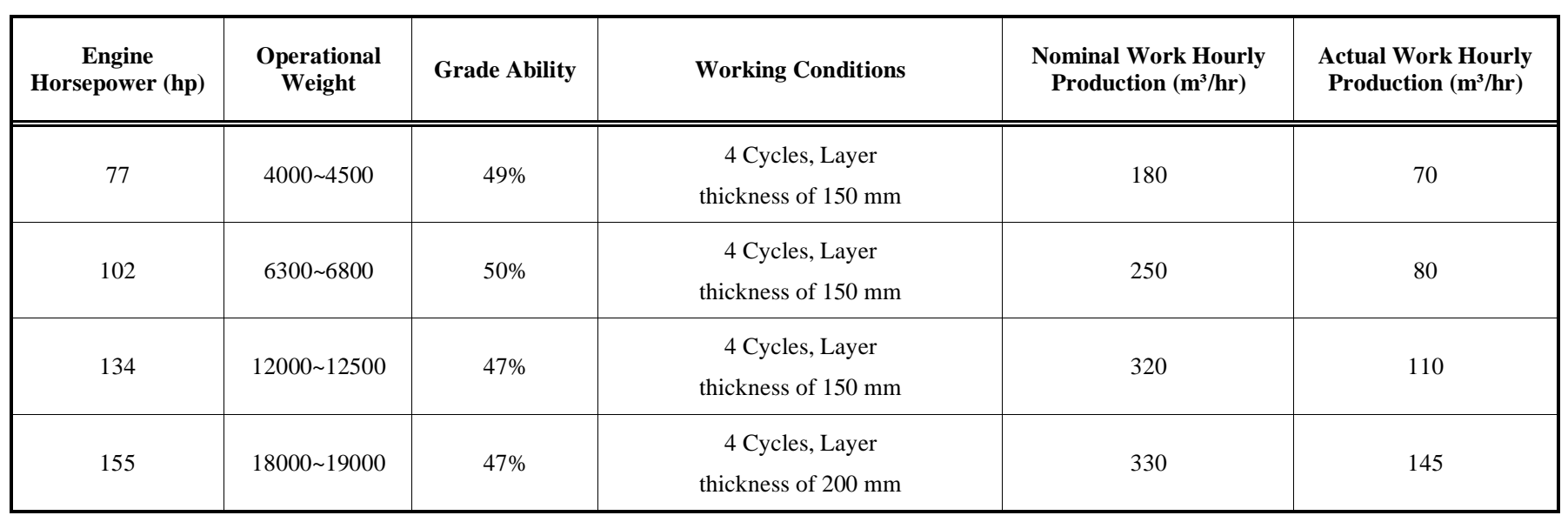


Table 5. Dozer Hourly Production

\begin{tabular}{|c|c|c|c|c|c|}
\hline $\begin{array}{c}\text { Engine } \\
\text { Horsepower (hp) }\end{array}$ & $\begin{array}{c}\text { Bucket } \\
\text { Capacity }\left(\mathbf{m}^{3}\right)\end{array}$ & Working Condition & Haul Distance & $\begin{array}{l}\text { Nominal Work Hourly } \\
\text { Production }\left(\mathrm{m}^{3} / \mathrm{hr}\right)\end{array}$ & $\begin{array}{l}\text { Actual Work Hourly } \\
\text { Production }\left(\mathbf{m}^{3} / \mathbf{h r}\right)\end{array}$ \\
\hline \multirow{3}{*}{105} & \multirow{3}{*}{2} & \multirow{3}{*}{ Common Earth, $0^{\circ}$ Slope } & 15 & 250 & 150 \\
\hline & & & 30 & 150 & 80 \\
\hline & & & 75 & 70 & 35 \\
\hline \multirow{3}{*}{124} & \multirow{3}{*}{$2.21 \sim 2.66$} & \multirow{3}{*}{ Common Earth, $0^{\circ}$ Slope } & 15 & 330 & 180 \\
\hline & & & 30 & 210 & 100 \\
\hline & & & 45 & 150 & 70 \\
\hline \multirow{3}{*}{130} & \multirow{3}{*}{2.7} & \multirow{3}{*}{ Common Earth, $0^{\circ}$ Slope } & 15 & 375 & 220 \\
\hline & & & 30 & 245 & 125 \\
\hline & & & 75 & 110 & 60 \\
\hline \multirow{3}{*}{165} & \multirow{3}{*}{$3.5 \sim 3.89$} & \multirow{3}{*}{ Common Earth, $0^{\circ}$ Slope } & 15 & 500 & 260 \\
\hline & & & 30 & 320 & 145 \\
\hline & & & 45 & 220 & 107 \\
\hline \multirow{3}{*}{225} & \multirow{3}{*}{$5.2 \sim 8.34$} & \multirow{3}{*}{ Common Earth, $0^{\circ}$ Slope } & 15 & 680 & 400 \\
\hline & & & 30 & 425 & 255 \\
\hline & & & 45 & 350 & 160 \\
\hline \multirow{3}{*}{285} & \multirow{3}{*}{10.98} & \multirow{3}{*}{ Common Earth, $0^{\circ}$ Slope } & 15 & 1200 & 720 \\
\hline & & & 45 & 540 & 297 \\
\hline & & & 135 & 180 & 100 \\
\hline \multirow{3}{*}{302} & \multirow{3}{*}{8.8} & \multirow{3}{*}{ Common Earth, $0^{\circ}$ Slope } & 15 & 1000 & 850 \\
\hline & & & 30 & 630 & 470 \\
\hline & & & 75 & 280 & 195 \\
\hline \multirow{3}{*}{370} & \multirow{3}{*}{14.4} & \multirow{3}{*}{ Common Earth, $0^{\circ}$ Slope } & 15 & 1400 & 1100 \\
\hline & & & 45 & 700 & 420 \\
\hline & & & 150 & 250 & 80 \\
\hline \multirow{3}{*}{410} & \multirow{3}{*}{15.1} & \multirow{3}{*}{ Common Earth, $0^{\circ}$ Slope } & 15 & 1480 & 1150 \\
\hline & & & 30 & 910 & 650 \\
\hline & & & 75 & 440 & 250 \\
\hline \multirow{3}{*}{525} & & & 15 & 1820 & 1300 \\
\hline & $18.5 \sim 20.9$ & Common Earth, $0^{\circ}$ Slope & 30 & 1150 & 730 \\
\hline & & & 45 & 950 & 485 \\
\hline & & & 30 & 1830 & 1300 \\
\hline 770 & $25.6 \sim 32.4$ & Common Earth, $0^{\circ}$ Slope & 45 & 1430 & 1100 \\
\hline & & & 135 & 500 & 300 \\
\hline & & & 30 & 2300 & 1500 \\
\hline 1050 & 45 & Common Earth, $0^{\circ}$ Slope & 75 & 1080 & 563 \\
\hline & & & 135 & 640 & 355 \\
\hline
\end{tabular}


Table 6. Wheel-Type Loader Hourly Production

\begin{tabular}{|c|c|c|c|c|}
\hline Engine Horsepower (hp) & Bucket Capacity $\left(\mathbf{m}^{3}\right)$ & Working Condition & $\begin{array}{l}\text { Nominal Work Hourly } \\
\text { Production }\left(\mathbf{m}^{3} / \mathbf{h r}\right)\end{array}$ & $\begin{array}{l}\text { Actual Work Hourly } \\
\text { Production }\left(\mathbf{m}^{3} / \mathbf{h r}\right)\end{array}$ \\
\hline 85 & $\begin{array}{c}1.2 \sim 1.4 \\
\text { General Purpose }\end{array}$ & $\begin{array}{l}\text { Loose soil, Average } \\
\text { Cycle Time } 0.45 \mathrm{~min}\end{array}$ & 160 & 100 \\
\hline 110 & $\begin{array}{c}1.7 \\
\text { General Purpose }\end{array}$ & $\begin{array}{l}\text { Loose soil, Average } \\
\text { Cycle Time } 0.45 \mathrm{~min}\end{array}$ & 225 & 135 \\
\hline 130 & $\begin{array}{c}2.1 \\
\text { General Purpose }\end{array}$ & $\begin{array}{l}\text { Loose soil, Average } \\
\text { Cycle Time } 0.45 \mathrm{~min}\end{array}$ & 260 & 150 \\
\hline 163 & $\begin{array}{c}2.5 \\
\text { General Purpose }\end{array}$ & $\begin{array}{l}\text { Loose soil, Average } \\
\text { Cycle Time } 0.45 \mathrm{~min}\end{array}$ & 300 & 175 \\
\hline 187 & $\begin{array}{c}3.1 \\
\text { General Purpose }\end{array}$ & $\begin{array}{l}\text { Loose soil, Average } \\
\text { Cycle Time } 0.45 \mathrm{~min}\end{array}$ & 350 & 215 \\
\hline 217 & $\begin{array}{c}3.1 \sim 3.7 \\
\text { General Purpose }\end{array}$ & $\begin{array}{l}\text { Loose soil, Average } \\
\text { Cycle Time } 0.45 \mathrm{~min}\end{array}$ & 380 & 225 \\
\hline 375 & $\begin{array}{c}6 \\
\text { General Purpose }\end{array}$ & $\begin{array}{l}\text { Loose soil, Average } \\
\text { Cycle Time } 0.45 \mathrm{~min}\end{array}$ & 630 & 350 \\
\hline 415 & $\begin{array}{c}5.7 \\
\text { Excavating Bucket }\end{array}$ & $\begin{array}{l}\text { Loose soil, Average } \\
\text { Cycle Time } 0.50 \mathrm{~min}\end{array}$ & 680 & 410 \\
\hline 640 & $\begin{array}{l}9.2 \\
\text { General Purpose }\end{array}$ & $\begin{array}{l}\text { Loose soil, Average } \\
\text { Cycle Time } 0.50 \mathrm{~min}\end{array}$ & 960 & 585 \\
\hline 789 & $\begin{array}{c}10.5 \\
\text { Excavating Bucket }\end{array}$ & $\begin{array}{l}\text { Loose soil, Average } \\
\text { Cycle Time } 0.50 \mathrm{~min}\end{array}$ & 1210 & 735 \\
\hline 828 & $\begin{array}{c}13 \\
\text { Excavating Bucket }\end{array}$ & $\begin{array}{l}\text { Loose soil, Average } \\
\text { Cycle Time } 0.50 \mathrm{~min}\end{array}$ & 1320 & 795 \\
\hline
\end{tabular}

Table 7. Crawler-Type Loader Hourly Production

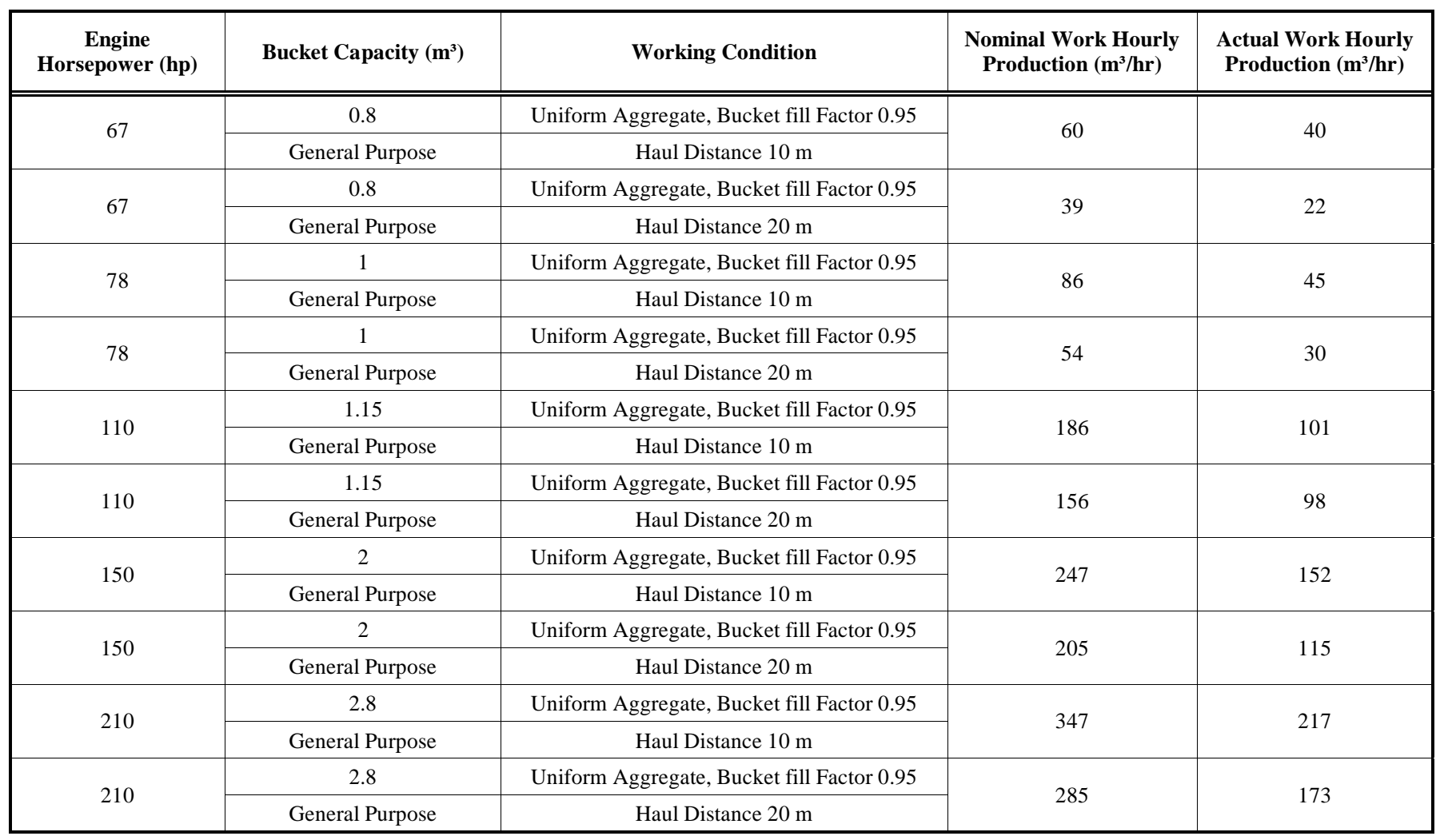


Table 8. Crawler-Type Excavator Hourly Production

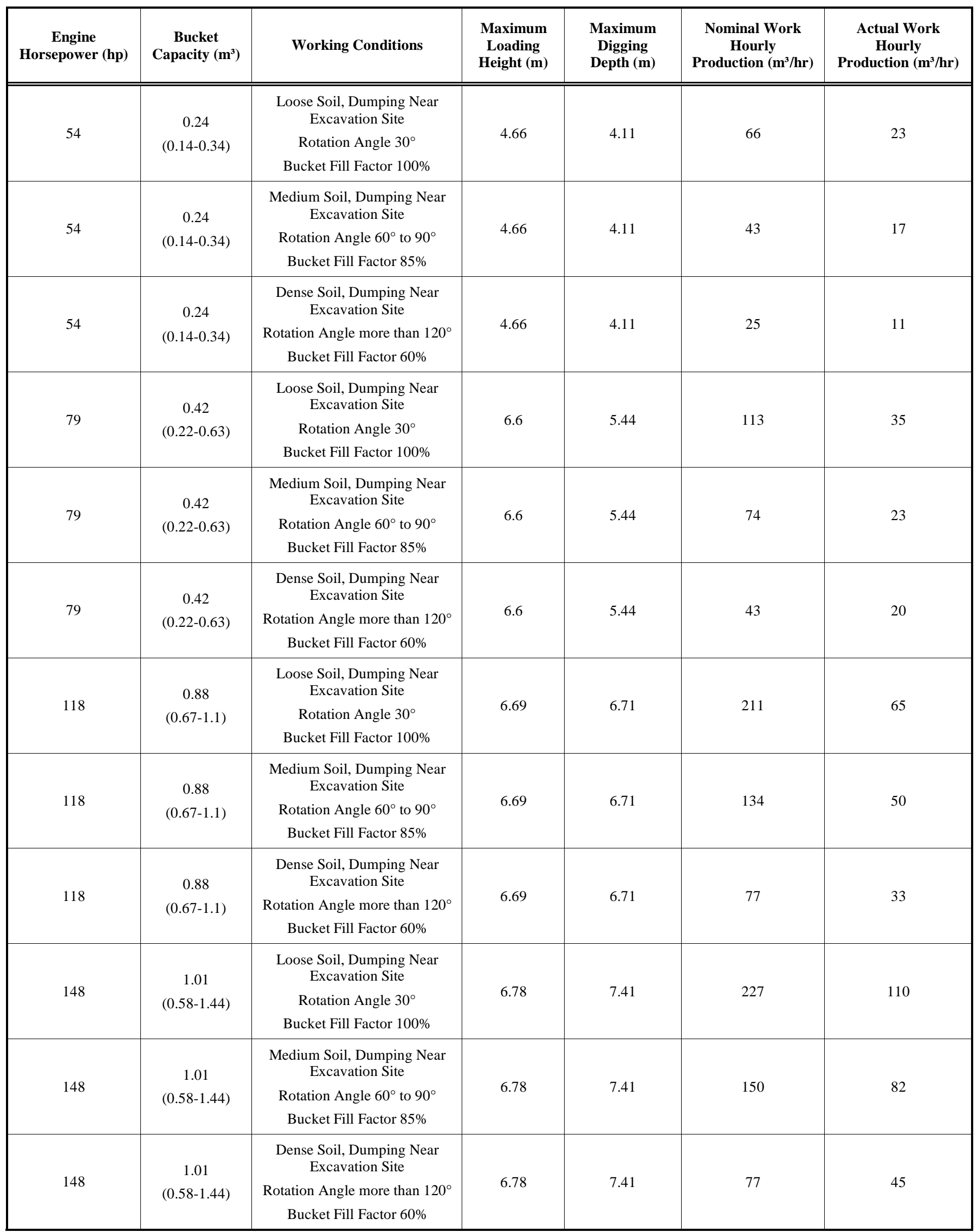


Table 8 contd....

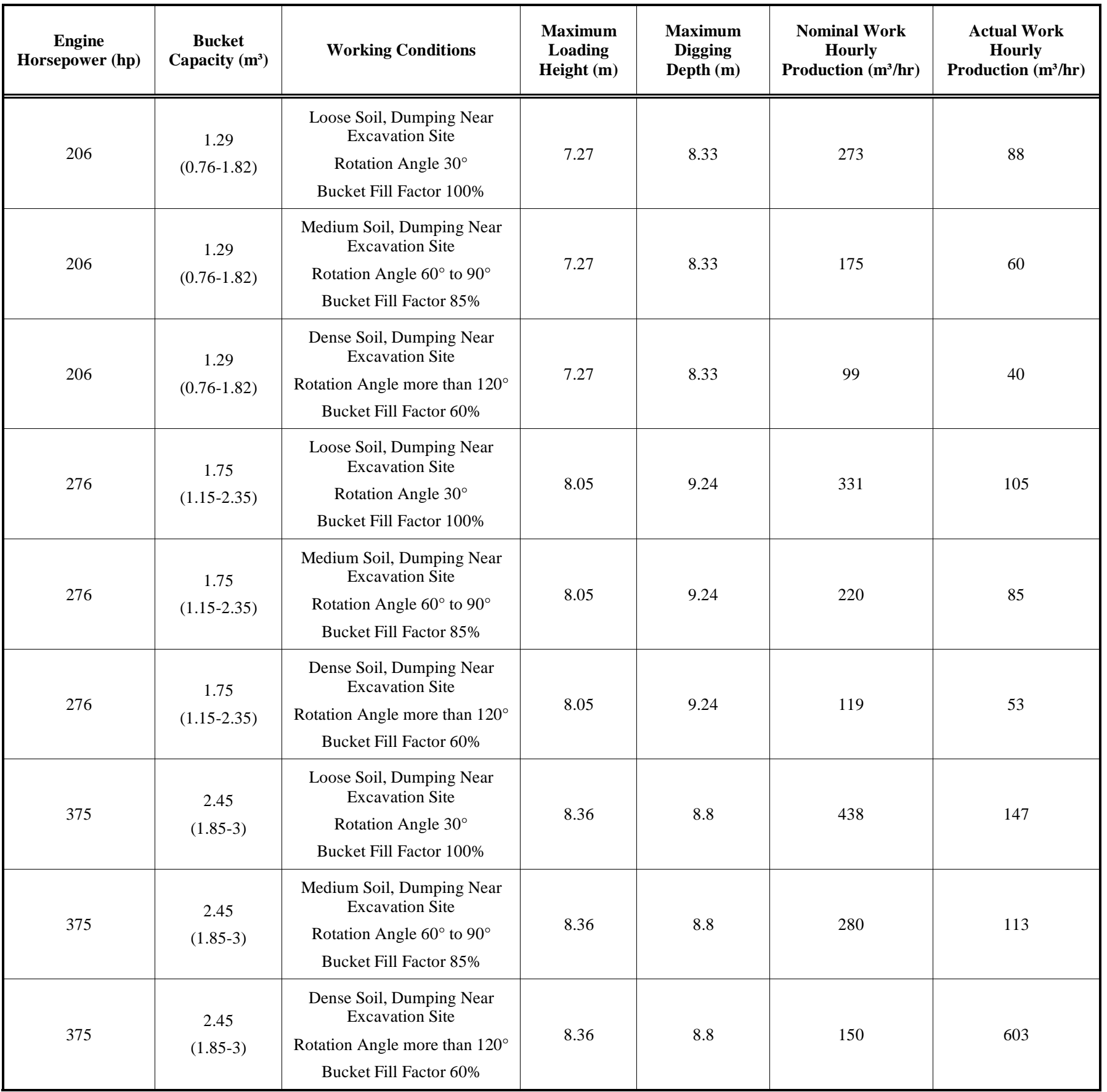

Table 9. Correction Factor for Working Conditions of All Equipment Types

\begin{tabular}{|c|c|}
\hline Working Condition & Factor \\
\hline \hline Good (50min per hour) & 0.83 \\
\hline Medium (45min per hour) & 0.75 \\
\hline Weak (40min per hour) & 0.67 \\
\hline Very weak (35min per hour) & 0.58 \\
\hline
\end{tabular}

Table 10. Material Correction Factor for A Dozer

\begin{tabular}{|c|c|}
\hline Type of Material & Factor \\
\hline \hline Loose soil & $0.9-1.1$ \\
\hline $\begin{array}{c}\text { Soil containig rubble stone, } \\
\text { fine rock aggregate }\end{array}$ & $0.7-0.9$ \\
\hline Cohesive clay, Hard ground & $0.6-0.7$ \\
\hline Blaster rock, Large rock slab & $0.4-0.6$ \\
\hline
\end{tabular}


Table 11. Ground Slope Correction Factor for A Dozer

\begin{tabular}{|c|c|}
\hline Ground Slope & Factor \\
\hline \hline 15 & 0.77 \\
\hline 10 & 0.86 \\
\hline 5 & 0.94 \\
\hline 0 & 1.00 \\
\hline-5 & 1.08 \\
\hline-10 & 1.14 \\
\hline-15 & 1.20 \\
\hline
\end{tabular}

Table 12. Bucket Fill Factor for A Loader

\begin{tabular}{|c|c|}
\hline Type of Material & Bucket Fill Factor \\
\hline \hline Moist loam & 1.00 \\
\hline Moist mixed loam & 0.95 \\
\hline Uniform aggregate & 0.95 \\
\hline $3 \mathrm{~mm}-9 \mathrm{~mm}$ & 0.90 \\
\hline $12 \mathrm{~mm}-20 \mathrm{~mm}$ & 0.85 \\
\hline 24 and over & 0.80 \\
\hline Bluster rock & 0.70 \\
\hline
\end{tabular}

\section{REFERENCES}

[2] S. Alkass, and F. Harris, "Expert system for earthmoving equipment selection in road construction", Construction Engineering and Management-ASCE, vol. 114, pp. 426-440, June 1989.

[3] S.N. Amirkhanian, and N.J. Baker, "Expert system for equipment selection for earth-moving operations", Construction Engineering and Management-ASCE, vol. 118, pp. 318-331, April 1992.

[4] S. Karshenas, and X. Feng, "Application of neural networks in earthmoving equipment production estimating", in: J.G. Barry, and R.W. Jeff, Eds. Proceedings of the 8th Conference Computing in Civil Engineering, 1992, pp. 841-847.

[5] S.D. Smith, "Earthmoving hourly production estimation using linear regression techniques", Construction Engineering and Management-ASCE, vol. 125, pp. 133-140, June 1999.

[6] C.O. Seung, and K.S. Sunil, "Construction equipment hourly production estimation using artificial neural network model", Construction Management and Economics, vol. 24, pp. 1029-1044, December 2006.

[7] C.D. Edmonds, B. Tsay, and W. Lin, "Analyzing machine efficiency", The National Public Accountant, vol. 39, pp. 28-44, December 1994.

[8] I. Bhurisith, and A. Touran, "Case study of obsolescence and equipment hourly production", Construction Engineering and Management-ASCE, vol. 128, pp. 357-361, October 2002.

[9] J. Zou, "HSV color-space digital image proceeding for the analysis of construction equipment utilization and for the maintenance of digital cities image inventory", MSc thesis, University of Alberta, Edmonton, Alberta, 2006.

[10] D. Arditi, S. Kale, and M. Tangkar, "Innovation in construction equipment and its flow into the construction industry", Construction Engineering and management-ASCE, vol. 123, pp. 371-378, April 1997.

[11] D. Gransberg, M. Popescu, and C. Ryan, Construction equipment management for engineers, estimators and owners. Florida: Taylor \& Francis, 2006

[12] J. Douglas, Construction equipment policy. New York: McGraw Hill, 1975.

[13] R.L. Peurifoy, C.J. Schexnayder, and A. Shapira, Construction planning, equipment, and methods. New York: McGraw Hill, 2006.

[14] JR. Stuart Wood, Heavy construction equipment and methods. New Jersey: Prentice-Hall, 1977.

Received: December 29, 2008

(C) Nabizadeh et al.; Licensee Bentham Open.

This is an open access article licensed under the terms of the Creative Commons Attribution Non-Commercial License (http://creativecommons.org/licenses/by-nc/3.0/) which permits unrestricted, non-commercial use, distribution and reproduction in any medium, provided the work is properly cited. 